\title{
ALDH2 genetic polymorphism and the risk of type II diabetes mellitus in CAD patients
}

\author{
Feng Xu${ }^{1}$, Yuguo Chen ${ }^{1}$, Ruijuan $\mathrm{Lv}^{1}$, He Zhang ${ }^{1}$, Hongbo Tian ${ }^{2}$, Yuan Bian ${ }^{1}$, Jinbo Feng ${ }^{3}$, Yi Sun ${ }^{1}$, \\ Ruijian $\mathrm{Li}^{1}$, Rong Wang ${ }^{3}$ and Yun $\mathrm{Zhang}^{3}$
}

The prevalence of type II diabetes mellitus (T2DM) in coronary artery disease (CAD) patients has been steadily increasing, especially in East Asian countries. Although many studies have suggested that certain genetic variants may predispose to the development of T2DM, very few studies investigated the genetic link with T2DM in CAD patients of East Asia. In this study, we investigated the relationship between Glu504Lys polymorphism in the acetaldehyde dehydrogenase 2 (ALDH2) gene, a key enzyme of alcohol metabolism, and the risk of having T2DM in Chinese Han CAD patients. We enrolled 542 CAD patients (180 women and 362 men) and 309 CAD-/DM - subjects ( 152 women and 157 men). T2DM was confirmed in $47.4 \%$ of CAD patients. Logistic and linear regression analyses showed that ALDH2 mutant genotypes $(* 1 / * 2$ and $* 2 / * 2)$ were an independent risk factor for both T2DM in female CAD patients, even after controlling for alcohol consumption (OR=1.95, $P=0.043)$, and fasting plasma glucose (FPG) in CAD-/DM - women $(P=0.015)$, whereas the association with FPG disappeared after controlling for high-sensitivity C-reactive protein, a classic inflammatory biomarker. However, there was no relationship between the ALDH2 genetic polymorphism and T2DM or FPG in men. These findings suggest that the ALDH2 polymorphism is associated with an increased risk of T2DM in female CAD patients, and this association could be causal on the basis of the association between the polymorphism and FPG, which is partly explained by an increased inflammatory status. These findings will benefit the screening and treatment of a high-risk population in East Asians.

Hypertension Research (2010) 33, 49-55; doi:10.1038/hr.2009.178; published online 30 October 2009

Keywords: acetaldehyde dehydrogenase 2; coronary artery disease; risk factor; single nucleotide polymorphism; type II diabetes mellitus

\section{INTRODUCTION}

Diabetes mellitus (DM) is a major risk factor and risk-equivalent of coronary artery disease (CAD). During the past decade, the prevalence of type II DM (T2DM) in CAD patients has increased significantly in all populations. It is reported that $35-55 \%$ of CAD patients have the complication of T2DM in Eastern and Western countries. ${ }^{1-6}$ Studies also suggest that CAD patients with $\mathrm{T} 2 \mathrm{DM}$ showed more serious and diffused coronary atherosclerotic lesions, with less collateral circulations, poor life quality and prognosis than did CAD patients without T2DM. ${ }^{7-9}$ These patients also suffered more major adverse coronary events, even after revascularization therapies. ${ }^{10-12}$ Therefore, more and more research efforts have focused on the prevalence, characteristics, predictors, etiologies, economic burdens and therapy strategies of CAD patients with T2DM. ${ }^{1-17}$ Recently, studies showed that countries in East Asia had similar and even higher prevalence of $\mathrm{T} 2 \mathrm{DM}$ in CAD patients compared with Western countries, although East Asians usually had a lower body mass index (BMI) and less hyperlipidemia. Mechanisms for this population-specific difference are not known.

Studies have suggested that drinking alcohol is associated with T2DM. However, associations between drinking and T2DM in different races and sexes are inconsistent, ${ }^{18-21}$ for which the difference in the distribution of genetic polymorphisms of drinking-related enzymes in different study populations is considered responsible. ${ }^{22}$ Acetaldehyde dehydrogenase 2 (ALDH2), a key enzyme of alcohol metabolism, shows a significant variation in a single-nucleotide polymorphism (SNP) in East Asians (30-50\% with the ALDH2 mutant allele) compared with Caucasians (lower than 5\%). ${ }^{23,24}$ ALDH2 is mainly located in the mitochondria and is encoded by the ALDH2 gene on chromosome 12. The ALDH2 gene is composed of 13 exons. In exon 12, there is a G-to-A missense mutation in which glutamate at position 504 is replaced by lysine (Glu504Lys); hence, there are two ALDH2 alleles (Glu504 and Lys504, also named ${ }^{\star} 1$ and ${ }^{\star} 2$, respectively, in many classic papers ${ }^{23,24}$ ) and three combinations,

\footnotetext{
${ }^{1}$ The Key Laboratory of Cardiovascular Remodeling and Function Research, Chinese Ministry of Education and Chinese Ministry of Public Health, Department of Emergency Medicine and Center of Chest Pain of Qilu Hospital, Shandong University, Jinan, China; ${ }^{2}$ The Key Laboratory of Cardiovascular Remodeling and Function Research, Chinese Ministry of Education and Chinese Ministry of Public Health, Shandong Province Hospital, Shandong University, Jinan, China and ${ }^{3}$ The Key Laboratory of Cardiovascular Remodeling and Function Research, Chinese Ministry of Education and Chinese Ministry of Public Health, Department of Cardiology of Qilu Hospital, Shandong University, Jinan, China

Correspondence: Dr Y Chen or Dr Y Zhang, Qilu Hospital of Shandong University, Wenhua Xi Road, Jinan, China.
}

E-mails: warmsunlight2006@yahoo.com.cn (Y Chen) or zhangyun@sdu.edu.cn (Y Zhang)

Received 13 August 2009; accepted 27 September 2009; published online 30 October 2009 
namely, ${ }^{\star} 1 /{ }^{\star} 1$ (wide-type homozygote), ${ }^{\star} 1 /{ }^{\star} 2$ (heterozygote) and ${ }^{\star} 2 /{ }^{\star} 2$ (mutant homozygote), in the population.

Previous studies have suggested that ALDH2 polymorphisms could be associated with increased risk of higher fasting plasma glucose (FPG), higher glycated hemoglobin Alc (HbAlc) or CAD; ${ }^{25-29}$ however, the direct evidence of this polymorphism in relation to T2DM in CAD patients is still absent. Given the fact that genetically determined disease susceptibility is frequently population specific, in this study, we investigated whether the ALDH2 gene SNP is related to T2DM in CAD patients among Han Chinese. We also studied the interactive effect with alcohol consumption. Our study showed a significant association between the ALDH2 polymorphism and T2DM in female CAD patients, which was independent of alcohol consumption and could be causal. Therefore, we also investigated the underlying preliminary mechanisms and found that inflammation might have a crucial role in this association.

\section{METHODS}

\section{Study population}

Patients diagnosed with CAD using coronary angiography in our hospital were enrolled from April 2007 to December 2007. These patients had at least one coronary lesion, with luminal diametrical stenosis $\geqslant 50 \%$ shown with coronary angiography. For further identification of associations between ALDH2 genotypes and T2DM in CAD, individuals without CAD and T2DM from the Health Exam Center of our hospital were also included consecutively, and the relationship between the ALDH2 gene SNP and FPG was analyzed. Eligibility criteria for subjects without $\mathrm{CAD}$ and $\mathrm{DM}$ included those without symptomatic and electrocardiogram evidence of myocardial ischemia, no past history of DM and FPG $<6.1 \mathrm{mmoll}^{-1}$. This study conformed to the ethical guidelines of the 1975 Declaration of Helsinki and was approved by our institution's ethics committee. All participants in this study provided signed informed consent. All blood samples were collected after more than an 8 -h fast.

\section{T2DM diagnosis}

The diagnosis and classification of T2DM were based on 1999 WHO criteria. T2DM patients belonged to two groups: (1) patients who were diagnosed with T2DM before admission and, (2), patients who were diagnosed with T2DM during hospitalization on the basis of FPG levels $\geqslant 7.0 \mathrm{mmoll}^{-1}$ in two consecutive tests or a standard oral glucose tolerance test.

\section{ALDH2 genotype detection}

The ALDH2 genetic polymorphism was detected as described in our previous paper in $2007 .{ }^{26}$ In brief, DNA was extracted from $200 \mu$ l of venous blood and extended using PCR. PCR products were purified and directly sequenced by an affiliated company of Invitrogen at Shanghai, China.

\section{Documentation of alcohol consumption}

The amount of beer, wine or liquor and the frequency of drinking per week during the participant's drinking lifetime were evaluated using a previously described method. ${ }^{30}$ Average daily alcohol consumption was calculated on the basis of the amount and frequency of consumption.

\section{Measurement of high-sensitivity C-reactive protein}

On the basis of the finding of a significant association between ALDH2 genotypes and FPG only in women, plasma levels of high-sensitivity C-reactive protein (hs-CRP), a classic inflammatory biomarker, were subsequently measured in women without $\mathrm{CAD}$ and $\mathrm{DM}$ using high-sensitivity latex-enhanced immunonephelometry.

\section{Statistical analysis}

All data were analyzed using SPSS 10.0 (SPSS Inc., Chicago, IL, USA). An $\chi^{2}$-test was used to determine whether the ALDH2 genotypes were in Hardy-Weinberg equilibrium. Student's $t$-test, $\chi^{2}$-test, nonparametric test, analysis of variance, logistic and linear regression analyses were used to analyze the associations between the ALDH2 genotypes and disease conditions. In the multiple regression analyses, we adjusted for the following risk factors of T2DM: age, BMI, frequency of vigorous physical activity $(<1,1-4$ or $\geqslant 5$ times per week), ${ }^{30}$ history of smoking, hypertension (defined as systolic blood pressure $\geqslant 140 \mathrm{~mm} \mathrm{Hg}$ and/or diastolic blood pressure $\geqslant 90 \mathrm{~mm} \mathrm{Hg}$ or treatment with antihypertensive medicine) and dyslipidemia. In this model, the presence of T2DM was the dependent variable. Two-tailed $P<0.05$ was deemed to be statistically significant.

\section{RESULTS}

Clinical characteristics of CAD patients and of subjects without CAD and DM

This study enrolled 542 CAD patients, including 180 women and 362 men. A total of $257(47.4 \%)$ CAD patients were confirmed to have T2DM. Of these T2DM patients, $162(63.0 \%)$ had been defined as T2DM before admission; the remaining 95 T2DM patients $(37.0 \%)$ were diagnosed for the first time during hospitalization according to the FPG level or on the basis of a standard oral glucose tolerance test. Furthermore, all known DM patients had been treated with oral hypoglycemic drugs or insulin therapy before admission, whereas the glucose levels of those DM patients classified during hospitalization were never controlled before admission. Of all CAD patients, 234 (43.2\%) had ALDH2 mutant genotypes $\left({ }^{\star} 1 /{ }^{\star} 2\right.$ or $\left.{ }^{\star} 2 /{ }^{\star} 2\right)$, including $211(38.9 \%)$ with ${ }^{\star} 1 /{ }^{\star} 2$ and $23(4.2 \%)$ with ${ }^{\star} 2 /{ }^{*} 2$. The ALDH2 genotypes of these patients were in Hardy-Weinberg equilibrium.

The clinical characteristics of CAD patients with and without T2DM are shown in Table 1. There were no significant differences in terms of sex, age, physical activity, smoking, hypertension, total cholesterol and low-density lipoprotein cholesterol between DM patients and non-DM patients. However, BMI, triglycerides (TGs), FPG and HbAlc were all remarkably higher, and high-density lipoprotein (HDL) cholesterol was lower in DM patients than in non-DM patients.

We also enrolled 309 individuals without CAD and T2DM (152 women and 157 men). Of these subjects, there were 208 (67.3\%) with ALDH2 genotype ${ }^{\star} 1 /{ }^{\star} 1$ and $101(32.7 \%)$ with ALDH2 genotype ${ }^{\star} 1 /{ }^{\star} 2$ or ${ }^{\star} 2 /{ }^{\star} 2$, which included $95(30.7 \%)$ with ${ }^{\star} 1 /{ }^{\star} 2$ and $6(1.9 \%)$ with ${ }^{\star} 2 /{ }^{\star}$. The ALDH2 genotypes of these people were in Hardy-Weinberg equilibrium.

\section{The ALDH2 SNP and alcohol consumption}

In both $\mathrm{CAD}$ patients and subjects without $\mathrm{CAD}$ and $\mathrm{DM}$, drinking at least once a week was common in men $(53.3 \%$ in CAD patients and $59.2 \%$ in subjects without $\mathrm{CAD}$ and $\mathrm{DM}$ ), but rare in women (only three in $\mathrm{CAD}$ patients and one among subjects without CAD and DM). Furthermore, men with ALDH2 genotype ${ }^{\star} 1{ }^{\star} 1$ had higher incidences of drinking at least once a week (67.5 vs. $36.4 \%$ in CAD patients, $P<0.001 ; 67.0$ vs. $43.2 \%$ in individuals without CAD and $\mathrm{DM}, P=0.004)$ and larger daily alcohol consumption compared with men with ALDH2 mutant genotypes $(P<0.001, P=0.011$, respectively).

\section{The ALDH2 SNP and T2DM in CAD patients}

Diabetes mellitus patients had a higher frequency of ALDH2 mutant genotypes compared with non-DM patients; the frequency of the ${ }^{\star} 2$ allele was higher in DM patients than in non-DM patients (Table 1). On including age, BMI, physical activity, smoking, hypertension, total cholesterol, TG, low-density lipoprotein and HDL as independent variables, logistic regression analysis showed that ALDH2 mutant genotypes were an independent risk factor for T2DM $(\mathrm{OR}=1.58$; $95 \% \mathrm{CI}=1.11-2.24 ; P=0.011)$. A similar result was shown after daily 
Table 1 Characteristics of CAD patients with or without T2DM

\begin{tabular}{|c|c|c|c|}
\hline Variable & $D M(\mathrm{n}=257)$ & Non-DM $(\mathrm{n}=285)$ & P-value \\
\hline \multicolumn{3}{|l|}{ CAD sub-types $(n, \%)$} & NS \\
\hline AMI & $75(29.2)$ & $72(25.3)$ & \\
\hline OMI & $19(7.4)$ & $17(6.0)$ & \\
\hline UA & $163(63.4)$ & $196(68.7)$ & \\
\hline Male $(n, \%)$ & $182(70.8)$ & $180(63.2)$ & NS \\
\hline Age (years) & $61.7 \pm 10.6$ & $60.9 \pm 10.2$ & NS \\
\hline BMI $\left(\mathrm{kg} \mathrm{m}^{-2}\right)$ & $25.9 \pm 3.0$ & $24.9 \pm 3.5$ & $<0.001$ \\
\hline \multicolumn{3}{|c|}{ Physical activity (times per week) ( $n, \%)$} & NS \\
\hline$<1$ & $162(63.0)$ & $166(58.3)$ & \\
\hline $1-4$ & $69(26.8)$ & $89(31.2)$ & \\
\hline$\geqslant 5$ & $26(10.1)$ & $30(10.5)$ & \\
\hline Smoking ( $n, \%)$ & $118(45.9)$ & $149(52.3)$ & NS \\
\hline Hypertension ( $n, \%)$ & $163(63.4)$ & $161(56.5)$ & NS \\
\hline $\mathrm{TC}\left(\mathrm{mmol} \mathrm{I}^{-1}\right)$ & $4.77 \pm 1.17$ & $4.72 \pm 1.12$ & NS \\
\hline $\mathrm{TG}(\mathrm{mmol} \mathrm{I-1})$ & $2.02 \pm 1.27$ & $1.73 \pm 0.92$ & 0.002 \\
\hline LDL-C (mmol I-1) & $2.93 \pm 0.92$ & $3.01 \pm 0.92$ & NS \\
\hline $\mathrm{HDL}-\mathrm{C}\left(\mathrm{mmoll}^{-1}\right)$ & $1.18 \pm 0.32$ & $1.24 \pm 0.37$ & 0.045 \\
\hline $\mathrm{FPG}\left(\mathrm{mmol} \mathrm{I}^{-1}\right)$ & $7.48 \pm 2.77$ & $5.19 \pm 0.64$ & $<0.001$ \\
\hline $\mathrm{HbAlc}(\%)$ & $7.04 \pm 1.32$ & $5.60 \pm 0.50$ & $<0.001$ \\
\hline $\operatorname{ALDH} 2 * 1 / * 2+* 2 / * 2(n, \%)$ & $126(49.0)$ & 108 (37.9) & 0.009 \\
\hline$* 2$ allele/* 1 allele $(n)$ & $141 / 373$ & $116 / 454$ & 0.007 \\
\hline Daily alcohol (g per day) & $23.7 \pm 58.2$ & $25.6 \pm 49.0$ & NS \\
\hline \multicolumn{3}{|c|}{ Frequency of drinking (days per week) $(n, \%)$} & NS \\
\hline$<1$ & $160(62.5)$ & $186(65.3)$ & \\
\hline $1-4$ & $56(21.5)$ & $47(16.5)$ & \\
\hline$\geqslant 5$ & $41(16.0)$ & $52(18.2)$ & \\
\hline
\end{tabular}

Abbreviations: ALDH2, acetaldehyde dehydrogenase 2; AMI, acute myocardial infarction; BMI, body mass index; CAD, coronary artery disease; FPG, fasting plasma glucose; HbAlc, hemoglobin Alc; HDL-C, high-density lipoprotein cholesterol; LDL-C, low-density lipoprotei cholesterol; NS, not significant; OMI, old myocardial infarction; TC, total cholesterol; T2DM, type II diabetes mellitus; TG, triglycerides; UA, unstable angina.

Data are represented as mean $+\mathrm{s} . \mathrm{d}$.

alcohol consumption and drinking frequency were included as confounding factors $(\mathrm{OR}=1.60 ; 95 \% \mathrm{CI}=1.12-2.29 ; P=0.009)$.

We further analyzed the possible gender-specific differences in relation to ALDH2 genotypes. The clinical characteristics of DM and non-DM subjects in female and male CAD patients are shown in Tables 2 and 3, respectively. In women, DM patients had a higher incidence of smoking, and higher levels of BMI, TG, FPG and HbAlc compared with non-DM patients. In men, the incidence of smoking and levels of TG, FPG and HbAlc were higher, whereas the level of HDL was lower in DM patients compared with non-DM patients. On including age, BMI, physical activity, smoking, hypertension, total cholesterol, TG, low-density lipoprotein and HDL as independent variables, logistic regression analysis showed that the ALDH2 mutant genotype was an independent predictor for T2DM only in women $(\mathrm{OR}=1.95 ; 95 \% \mathrm{CI}=1.04-3.71 ; P=0.043)$. A significant result was also obtained after daily alcohol consumption and drinking frequency were controlled for $(\mathrm{OR}=1.95 ; 95 \% \mathrm{CI}=1.04-3.71 ; P=0.043)$. No relationships were found in men regardless of whether daily alcohol consumption and drinking frequency were included $(P=0.365$ and $P=0.454$, respectively)

\section{ALDH2 SNPs, FPG and hs-CRP in women and men} without $\mathrm{CAD}$ and $\mathrm{DM}$

On the basis of the foregoing findings of gender-specific difference, we further investigated the relationship between ALDH2 SNPs and FPG
Table 2 Characteristics of 180 female CAD patients with or without T2DM

\begin{tabular}{|c|c|c|c|}
\hline Variable & $D M(\mathrm{n}=75)$ & Non-DM $(\mathrm{n}=105)$ & P-value \\
\hline \multicolumn{3}{|l|}{ CAD sub-types ( $n, \%)$} & NS \\
\hline $\mathrm{AMI}+\mathrm{OMI}$ & $17+1(24.0)$ & $19+1(19.0)$ & \\
\hline UA & $57(76.0)$ & $85(81.0)$ & \\
\hline Age (years) & $65.8 \pm 7.3$ & $63.9 \pm 9.0$ & NS \\
\hline $\mathrm{BMI}\left(\mathrm{kg} \mathrm{m}^{-2}\right)$ & $26.2 \pm 3.0$ & $24.2 \pm 2.9$ & $<0.001$ \\
\hline \multicolumn{3}{|c|}{ Physical activity (times per week) (n, \%) } & NS \\
\hline$<1$ & $50(66.7)$ & $58(55.2)$ & \\
\hline $1-4$ & $16(21.3)$ & $37(35.2)$ & \\
\hline$\geqslant 5$ & $9(12.0)$ & $10(9.5)$ & \\
\hline Smoking $(n, \%)$ & $2(2.7)$ & $13(12.4)$ & 0.020 \\
\hline Hypertension ( $n, \%$ ) & $53(70.7)$ & $69(65.7)$ & NS \\
\hline $\mathrm{TC}\left(\mathrm{mmol} \mathrm{I}{ }^{-1}\right)$ & $5.25 \pm 1.24$ & $4.96 \pm 1.21$ & NS \\
\hline $\mathrm{TG}\left(\mathrm{mmol} \mathrm{I}^{-1}\right)$ & $2.28 \pm 1.54$ & $1.84 \pm 1.01$ & 0.023 \\
\hline LDL-C (mmol I-1) & $3.02 \pm 0.96$ & $3.17 \pm 0.92$ & NS \\
\hline $\mathrm{HDL}-\mathrm{C}\left(\mathrm{mmol} \mathrm{I}^{-1}\right)$ & $1.44 \pm 0.37$ & $1.36 \pm 0.35$ & NS \\
\hline $\mathrm{FPG}\left(\mathrm{mmol} \mathrm{I}^{-1}\right)$ & $7.26 \pm 1.65$ & $5.20 \pm 0.60$ & $<0.001$ \\
\hline HbAlc (\%) & $6.97 \pm 1.17$ & $5.71 \pm 0.47$ & $<0.001$ \\
\hline $\mathrm{ALDH} 2 * 1 /{ }^{*} 2+{ }^{*} 2 /{ }^{*} 2(n, \%)$ & $37(49.3)$ & $32(30.5)$ & 0.010 \\
\hline$* 2$ allele/*1 allele $(n)$ & $40 / 110$ & $33 / 177$ & 0.011 \\
\hline \multicolumn{3}{|c|}{ Frequency of drinking (days per week) ( $n, \%)$} & - \\
\hline$<1$ & 74 & 103 & \\
\hline $1-4$ & 1 & 2 & \\
\hline$\geqslant 5$ & 0 & 0 & \\
\hline
\end{tabular}

Abbreviations: ALDH2, acetaldehyde dehydrogenase 2; AMI, acute myocardial infarction; BMI, body mass index; CAD, coronary artery disease; FPG, fasting plasma glucose; $\mathrm{HbAlc}$

hemoglobin A1c; HDL-C, high-density lipoprotein cholesterol; LDL-C, low-density lipoprotein cholesterol; NS, not significant; OMI, old myocardial infarction; TC, total cholesterol; T2DM, type II diabetes mellitus; TG, triglycerides; UA, unstable angina.

in women and men without CAD and DM, respectively. Tables 4 and 5 show the clinical characteristics of these women and men in relation to their ALDH2 genotypes. Women with ALDH2 mutant genotypes had a higher FPG compared with women with the common ${ }^{\star} 1 /{ }^{\star} 1$ allele. However, men with mutant ALDH2 genotypes had similar FPG compared with men with the ${ }^{\star} 1 /{ }^{\star} 1$ allele. After adjusting for age, BMI, physical activity and smoking, FPG levels in the female individuals with ALDH2 mutant genotypes were significantly higher than those in female ${ }^{\star} 1{ }^{\star} 1$ subjects, whereas FPG levels were similar in men with different ALDH2 genotypes (Figure 1). After including age, BMI, physical activity, smoking, hypertension, total cholesterol, TG, lowdensity lipoprotein and HDL as independent variables, linear regression analyses showed an association between the ALDH2 SNP and FPG in women $(P=0.015)$, but there was no relationship in men. A nonsignificant association was also evident in men after controlling for daily alcohol consumption. Alcohol consumption was not controlled in the subanalysis of females, as there was only one woman who consumed alcohol regularly. Subsequently, we also detected the levels of hs-CRP in women, and it was determined that women with mutant ALDH2 genotypes had higher hs-CRP levels than those with ${ }^{\star} 1 /{ }^{\star} 1$ (Table 4). Moreover, when hs-CRP was also included for adjustment, linear regression analysis showed that there was no relationship between ALDH2 genotypes and FPG in women $(P=0.162)$.

\section{DISCUSSION}

Our study shows that the ALDH2 polymorphism is associated with an increased risk of T2DM in female CAD patients, and this association 
Table 3 Characteristics of 362 male CAD patients with or without T2DM

\begin{tabular}{|c|c|c|c|}
\hline Variable & $D M(\mathrm{n}=182)$ & Non-DM $(\mathrm{n}=180)$ & P-value \\
\hline \multicolumn{3}{|l|}{$C A D$ subtype $(n, \%)$} & NS \\
\hline AMI & $58(29.4)$ & $53(30.3)$ & \\
\hline OMI & $18(8.9)$ & $16(9.2)$ & \\
\hline UA & $106(61.7)$ & $111(60.5)$ & \\
\hline Age (years) & $60.6 \pm 11.1$ & $59.2 \pm 10.5$ & NS \\
\hline BMI $\left(\mathrm{kg} \mathrm{m}^{-2}\right)$ & $25.8 \pm 3.0$ & $25.3 \pm 3.8$ & NS \\
\hline \multicolumn{3}{|c|}{ Physical activity (times per week) (n, \%) } & NS \\
\hline$<1$ & $112(61.5)$ & $108(60)$ & \\
\hline $1-4$ & $53(29.1)$ & $52(28.9)$ & \\
\hline$\geqslant 5$ & $17(9.3)$ & $20(11.1)$ & \\
\hline Smoking $(n, \%)$ & $116(63.7)$ & $136(75.6)$ & 0.014 \\
\hline Hypertension $(n, \%)$ & $110(60.4)$ & $92(51.1)$ & NS \\
\hline $\mathrm{TC}\left(\mathrm{mmol} \mathrm{I}^{-1}\right)$ & $4.58 \pm 1.09$ & $4.58 \pm 1.05$ & NS \\
\hline $\mathrm{TG}\left(\mathrm{mmol} \mathrm{I}^{-1}\right)$ & $1.92 \pm 1.12$ & $1.67 \pm 0.87$ & 0.016 \\
\hline LDL-C (mmol I-1) & $2.90 \pm 0.91$ & $2.90 \pm 0.90$ & NS \\
\hline $\mathrm{HDL}-\mathrm{C}\left(\mathrm{mmol} \mathrm{I}^{-1}\right)$ & $1.08 \pm 0.24$ & $1.16 \pm 0.37$ & 0.015 \\
\hline FPG $\left(\mathrm{mmol}^{-1}\right)$ & $7.60 \pm 3.25$ & $5.17 \pm 0.67$ & $<0.001$ \\
\hline $\mathrm{HbA} 1 \mathrm{c}(\%)$ & $7.07 \pm 1.38$ & $5.55 \pm 0.50$ & $<0.001$ \\
\hline $\operatorname{ALDH} 2 * 1 / * 2+* 2 / * 2(n, \%)$ & $89(48.9)$ & $76(42.2)$ & NS \\
\hline$* 2$ allele/*1 allele $(n)$ & $101 / 263$ & $83 / 277$ & NS \\
\hline Daily alcohol (g per day) & $31.4 \pm 62.6$ & $37.5 \pm 52.9$ & NS \\
\hline \multicolumn{3}{|c|}{ Frequency of drinking (days per week) $(n, \%)$} & NS \\
\hline$<1$ & $86(47.3)$ & $83(46.1)$ & \\
\hline $1-4$ & $55(30.2)$ & $45(25.0)$ & \\
\hline$\geqslant 5$ & $41(22.5)$ & $52(28.9)$ & \\
\hline
\end{tabular}

Abbreviations: ALDH2, acetaldehyde dehydrogenase 2; AMI, acute myocardial infarction; BMI body mass index; CAD, coronary artery disease; FPG, fasting plasma glucose; HbAlc, hemoglobin Alc; HDL-C, high-density lipoprotein cholesterol; LDL-C, low-density lipoprotein cholesterol; NS, not significant; OMI, old myocardial infarction; TC, total cholesterol; T2DM, type II diabetes mellitus; TG, triglycerides; UA, unstable angina.

could be causal on the basis of the significant correlation between this polymorphism and FPG. Moreover, this causal relationship might be partly explained by inflammation, as shown by elevated hs-CRP levels. Previous studies have shown that a significant proportion of CAD patients had undiagnosed T2DM until hospitalization. ${ }^{1-6}$ Taubert's study in Germany showed that $46.6 \%$ of DM patients were not diagnosed previously in high-risk CAD patients scheduled for coronary angiography. ${ }^{1}$ A recent Chinese heart survey by $\mathrm{Hu}$ et al. ${ }^{4}$ showed that undiagnosed T2DM accounted for nearly $40 \%$ of all T2DM patients in hospitalized CAD patients. In our study, the rate of newly diagnosed T2DM during hospitalization was $37.0 \%$, which is consistent with Hu's study. Previous studies also showed that coronary artery lesions and prognosis were worse in CAD patients with newly diagnosed DM than in nondiabetic patients, and were even worse compared with known DM patients because the risk factors had been poorly controlled on the basis of delayed diagnosis. ${ }^{1-3,11,12,31}$ Obviously, both known DM patients and previously unrecognized DM patients should be considered to be equally important. In this study, the previously known and unknown DM patients were both included in the DM group.

Studies have further shown that drinking alcohol is associated with the presence of T2DM, although findings are inconsistent in Western and Eastern populations. ${ }^{19-21}$ In addition, the association of drinking and T2DM also seems to have a different role between women and men in relation to the risk of diabetes and CAD. ${ }^{18-20}$ The difference in
Table 4 Characteristics of 152 women without CAD and DM

\begin{tabular}{|c|c|c|c|}
\hline Variable & ${ }^{*} 1 /{ }^{*} 2+{ }^{*} 2 /{ }^{*}(n=50)$ & ${ }^{*} 1 /{ }^{*} 1(\mathrm{n}=102)$ & P-value \\
\hline Age (years) & $61.7 \pm 9.0$ & $63.5 \pm 9.6$ & NS \\
\hline BMI $\left(\mathrm{kg} \mathrm{m}^{-2}\right)$ & $24.9 \pm 3.9$ & $25.2 \pm 3.1$ & NS \\
\hline \multicolumn{3}{|c|}{ Physical activity (times per week) (n, \%) } & NS \\
\hline$<1$ & $26(52.0)$ & $50(49.0)$ & \\
\hline $1-4$ & $15(30.0)$ & $32(31.4)$ & \\
\hline$\geqslant 5$ & $9(18.0)$ & $20(19.6)$ & \\
\hline Smoking $(n, \%)$ & $6(12.0)$ & $8(7.8)$ & NS \\
\hline Hypertension ( $n, \%)$ & $15(30.0)$ & $20(19.6)$ & NS \\
\hline $\mathrm{TC}\left(\mathrm{mmol} \mathrm{I}{ }^{-1}\right)$ & $5.16 \pm 1.20$ & $5.38 \pm 0.98$ & NS \\
\hline $\mathrm{TG}\left(\mathrm{mmol} \mathrm{I}^{-1}\right)$ & $1.57 \pm 0.63$ & $1.72 \pm 0.77$ & NS \\
\hline LDL-C (mmol I-1) & $2.65 \pm 1.20$ & $2.79 \pm 1.09$ & NS \\
\hline HDL-C $\left(\mathrm{mmol} \mathrm{I}^{-1}\right)$ & $1.79 \pm 1.02$ & $1.97 \pm 1.04$ & NS \\
\hline $\mathrm{FPG}\left(\mathrm{mmol} \mathrm{I}^{-1}\right)$ & $5.28 \pm 0.62$ & $4.81 \pm 0.60$ & $<0.001$ \\
\hline \multicolumn{3}{|c|}{ Frequency of drinking (days per week) ( $n, \%)$} & - \\
\hline$<1$ & 50 & 101 & \\
\hline $1-4$ & 0 & 1 & \\
\hline$\geqslant 5$ & 0 & 0 & \\
\hline hs-CRP $\left(\left.m g\right|^{-1}\right)$ & $2.56 \pm 1.80$ & $1.70 \pm 2.78$ & $<0.001$ \\
\hline
\end{tabular}

Table 5 Characteristics of 157 men without CAD and DM

\begin{tabular}{|c|c|c|c|}
\hline Variable & $* 1 / * 2+* 2 / * 2(n=51)$ & ${ }^{*} 1 /{ }^{*} 1(n=106)$ & P-value \\
\hline Age (years) & $60.2 \pm 10.4$ & $60.3 \pm 11.0$ & NS \\
\hline $\mathrm{BMI}\left(\mathrm{kg} \mathrm{m}^{-2}\right)$ & $24.8 \pm 4.5$ & $25.4 \pm 4.1$ & NS \\
\hline \multicolumn{3}{|c|}{ Physical activity (times per week) (n, \%) } & NS \\
\hline$<1$ & $31(60.8)$ & $63(59.4)$ & \\
\hline $1-4$ & $16(31.4)$ & $32(30.2)$ & \\
\hline$\geqslant 5$ & $4(7.8)$ & $11(10.4)$ & \\
\hline Smoking $(n, \%)$ & $43(84.3)$ & $70(66.0)$ & 0.028 \\
\hline Hypertension ( $n, \%)$ & $13(25.5)$ & $28(26.4)$ & NS \\
\hline $\mathrm{TC}\left(\mathrm{mmol} \mathrm{I}{ }^{-1}\right)$ & $5.22 \pm 1.05$ & $5.12 \pm 0.85$ & NS \\
\hline $\mathrm{TG}\left(\mathrm{mmol} \mathrm{I}^{-1}\right)$ & $1.72 \pm 1.35$ & $1.68 \pm 0.84$ & NS \\
\hline LDL-C (mmol I-1) & $3.15 \pm 0.67$ & $3.14 \pm 0.67$ & NS \\
\hline $\mathrm{HDL}-\mathrm{C}\left(\mathrm{mmol} \mathrm{I}^{-1}\right)$ & $1.42 \pm 0.37$ & $1.34 \pm 0.58$ & NS \\
\hline $\mathrm{FPG}\left(\mathrm{mmol} \mathrm{I}^{-1}\right)$ & $5.06 \pm 0.65$ & $5.06 \pm 1.22$ & NS \\
\hline Daily alcohol (g per day) & $10.5 \pm 14.6$ & $12.6 \pm 28.6$ & 0.011 \\
\hline \multicolumn{3}{|c|}{ Frequency of drinking (days per week) ( $n, \%$ ) } & 0.010 \\
\hline$<1$ & 29 (56.9) & $35(33.0)$ & \\
\hline $1-4$ & $16(31.4)$ & $42(39.6)$ & \\
\hline$\geqslant 5$ & $6(11.8)$ & $29(27.4)$ & \\
\hline
\end{tabular}

Abbreviations: BMI, body mass index; CAD, coronary artery disease; DM, diabetes mellitus; FPG, fasting plasma glucose; HDL-C, high-density lipoprotein cholesterol; LDL-C, low-density lipoprotein cholesterol; NS, not significant; TC, total cholesterol; TG, triglycerides.

the distribution of genetic polymorphisms of alcohol-related enzymes may be a crucial cause for the different results in Eastern and Western countries. ${ }^{22}$ Moreover, these genetic polymorphisms may have different effects in women and men because of their different patterns in alcohol consumption. 


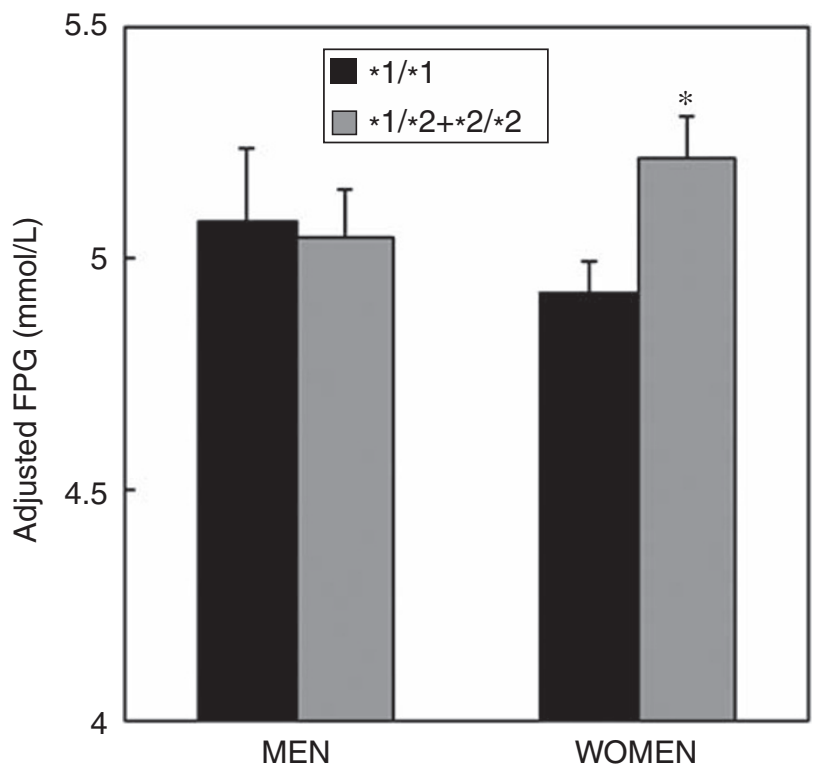

Figure 1 Fasting plasma glucose (FPG) in male and female subjects without coronary artery disease (CAD) and diabetes mellitus (DM) after adjustment for age, body mass index (BMI), physical activity and smoking. ${ }^{*} P<0.001$.

The Glu504Lys genetic polymorphism of ALDH2, a key enzyme of alcohol metabolism, is common in East Asians. ${ }^{23,24}$ Previous studies showed that ALDH2 activity from either genotype ${ }^{\star} 1{ }^{\star} 2$ or ${ }^{\star} 2 /{ }^{\star} 2$ decreased significantly compared with that of the ALDH2 ${ }^{\star} 1 /{ }^{\star} 1$ genotype. ${ }^{23}$ Our study showed that $43.2 \%$ and $32.7 \%$ of CAD patients and subjects without CAD and DM, respectively, had the ALDH2 ${ }^{*} 2$ allele; most subjects with the ALDH2 2 *2 allele were heterozygous (38.9\% in CAD patients and $30.7 \%$ in subjects without CAD and $\mathrm{DM})$. Owing to the similar activities of ALDH $2{ }^{\star} 1 /{ }^{\star} 2$ and ${ }^{\star} 2{ }^{\star} * 2$ alleles and the characteristic of genetic polymorphism distribution in the Chinese, we considered ALDH2 genotypes ${ }^{\star} 1 /{ }^{\star} 2$ and ${ }^{\star} 2 /{ }^{\star} 2$ as a group, which was then compared with genotype ${ }^{\star} 1 /{ }^{\star} 1$ in this study.

Earlier studies have shown that the ALDH2 genetic polymorphism has an important role in several pathological conditions, including hepatitis and certain types of carcinomas. ${ }^{32,33}$ Recent studies, including a pilot study of ours, suggested that this polymorphism was also associated with $\mathrm{CAD} .{ }^{26-28}$ In this study, we further investigated the association of the ALDH2 gene SNP with the coexistence of T2DM in $\mathrm{CAD}$ patients, and their relevance to alcohol consumption. To our knowledge, this is the first study in a Chinese population. Most studies on Asians showed that the ALDH2 gene SNP influenced drinking dramatically, whereas some studies, mainly in Japan, did not support this association..$^{28,34}$ These inconsistent reports could be explained by different drinking cultures in different countries. ${ }^{35,36}$ It has been shown that the Japanese, especially Japanese males, usually have a more distinctive drinking culture than do the Chinese. ${ }^{35,36}$ In our study, the ALDH2 genetic polymorphism was significantly associated with alcohol consumption. We further showed that for both CAD patients and subjects without CAD and DM, men with ALDH2 genotypes ${ }^{\star} 1 /{ }^{\star} 2$ and ${ }^{\star} 2{ }^{\star} 2$ had significantly less alcohol consumption than those with ${ }^{\star} 1{ }^{\star} 1$; only few women drank alcohol frequently. These results are consistent with other studies on the Chinese. ${ }^{37,38}$

In this study, we also found that there was a higher prevalence of ALDH2 mutant genotypes in DM patients than in non-DM patients; binary logistic regression analysis showed that ALDH2 mutant genotypes were independent risk factors of $\mathrm{T} 2 \mathrm{DM}$ in $\mathrm{CAD}$ patients.
However, when we analyzed the relationships between ALDH2 genetic SNP and T2DM separately in female and male CAD patients, there was no difference in the prevalence of ALDH2 mutant genotypes in men with and without DM, whereas there was a significant difference in women with DM and non-DM. Furthermore, logistic regression analysis also indicated that ALDH2 mutant genotypes were independent risk factors for T2DM only in female CAD patients even after including daily alcohol consumption and drinking frequency as independent variables. These results suggest that there is a significant association between the ALDH2 genetic polymorphism and T2DM in female CAD patients, which is independent of alcohol consumption.

For further identification of the potential causal correlation between $\mathrm{ALDH} 2$ genotypes and T2DM in CAD, we also investigated the effect of the ALDH2 genetic polymorphism on FPG. A total of 309 individuals without $\mathrm{CAD}$ and $\mathrm{DM}$ were enrolled as study subjects to exclude the confounding of hypoglycemic medication. Our study showed that there was a markedly higher FPG level only in female cases with the mutant ALDH2 genotype compared with those with ${ }^{\star} 1 /{ }^{\star} 1$. The same result was obtained after adjusting for age, BMI, smoking and physical activity. Linear regression analysis further showed that the ALDH2 mutant genotype was an independent risk factor for FPG in women only; this association could not be explained by alcohol consumption because almost none of these women drank alcohol frequently. These findings indicated that the association of the ALDH2 genetic polymorphism with T2DM in CAD patients of women should be causal.

Recently, a study by Dakeishi et al. ${ }^{25}$ also suggested a statistical correlation between the ALDH2 Gly504Lys polymorphism and FPG independent of alcohol consumption in Japanese women, but no relation was found in Japanese men. These conclusions are similar to ours. In contrast, an earlier study by Murata et al. ${ }^{29}$ showed that inactive ALDH2 was associated with a higher HbA1c in Japanese men, and the effect of ALDH2 on the amount of alcohol consumed might have an important role in this association. This result seems to be inconsistent with ours and Dakeishi's. However, in Murata's study, the difference in HbAlc only existed in patients who drank a similar amount of alcohol whatever be their genotypes of ALDH2, and HbA1c levels were similar between all active and inactive ALDH2 patients. This indicates that Murata's conclusion is actually that the patients with an inactive ALDH2 genotype, but who still drink frequently, suffer a higher risk of high HbAlc. On the other hand, the impact of genetic polymorphisms of multiple key enzymes of alcohol metabolism on FPG might also partly explain this confusion. Similar to the results of Dakeishi's study, genetic polymorphism of alcohol dehydrogenase 2, another key enzyme of alcohol metabolism, had a significant association with FPG in Japanese men, and this polymorphism was not considered as a confounding factor in Murata's study. Thus, a large prospective study of evaluation with regard to various polymorphisms of drinking-related enzymes is necessary to further determine all these findings.

A recent study suggests that ALDH2 with different activities could have different effects on oxidative stress factors. ${ }^{24}$ This in vitro study showed that an activator of ALDH2 could improve the activities of both wild-type and mutant ALDH2 and then reduce the level of 4-hydroxynonenal, an oxidative stress-induced cytotoxic aldehyde. Another recent study revealed that the dehydrogenase activities for $\mathrm{ALDH} 2{ }^{\star} 2 /{ }^{\star} 2$ and ${ }^{\star} 1 /{ }^{\star} 2$ were only $2-15 \%$ of the $\mathrm{ALDH} 2{ }^{\star} 1 /{ }^{\star} 1$ activity. ${ }^{23}$ Previous studies have shown that oxidative stress was an important consequence of inflammation, and inflammation influenced insulin resistance significantly. ${ }^{39,40}$ We hypothesized that $\mathrm{ALDH} 2$ from different genotypes might influence insulin resistance, 
FPG and subsequent DM by a different effect on inflammation. Therefore, we assessed the impact of ALDH2 Glu504Lys polymorphism on hs-CRP levels in women without CAD and DM in this study. We found a significant difference in hs-CRP levels in women with different ALDH2 genotypes; linear regression analysis showed that the association between ALDH2 genetic polymorphism and FPG disappeared after adjusting for traditional DM risk factors, as well as for hs-CRP. These findings supported our hypothesis that inflammation may be an important mediator for the observed association between ALDH2 polymorphism and FPG. A more recent study in mice also suggested that ALDH2 transgenic overexpression reduced myocardial insulin resistance, which further supports our hypothesis. $^{41}$ Insulin resistance in this model was induced by alcohol ingestion, which suggests that ALDH2 might influence insulin resistance by its effect on alcohol metabolism. ${ }^{41}$ However, our study indicates that there is a direct impact of ALDH2 polymorphism on hs-CRP levels independent of drinking, as only one female consumed alcohol regularly. Of course, the underlying molecular mechanisms between ALDH2 and DM should be investigated further. Our study is limited by a relatively small sample size, few biomarkers and the absence of in vivo and in vitro functional studies.

In conclusion, we found that ALDH2 mutant genotypes $\left({ }^{\star} 1{ }^{\star} 2\right.$ and ${ }^{\star} 2{ }^{*} 2$ ) were independent risk factors for the coexistence of T2DM in female CAD patients and were also independent risk factors for FPG in women without $\mathrm{CAD}$ and $\mathrm{DM}$. The fact that the association between ALDH2 polymorphism and FPG disappeared after controlling for hs-CRP suggests that increased inflammation may explain the association. On the other hand, there was no association between the ALDH2 genetic polymorphism and T2DM or FPG in men. The findings in women without CAD and DM suggest that the association between ALDH2 mutant genotypes and T2DM in female CAD patients could be causal; the causal correlation could be partly explained by inflammatory status. These findings are valuable for the understanding of a pathogenic link between CAD and T2DM in East Asians, which could lead to a more effective management of the conditions. Considering the nature of multifactorial pathogenesis of DM, the importance of the ALDH2 Glu504Lys polymorphism needs to be further investigated in prospective studies of different populations.

\section{CONFLICT OF INTEREST}

The authors declare no conflict of interest.

\section{ACKNOWLEDGEMENTS}

This work was supported by a grant from the Department of Science and Technology of Shandong Province, China (grant number Y2007C075), by a grant for Excellent Medical Subject Leaders from the Health Department of Shandong Province in China and by the Cultivation Fund of the Key Scientific and Technical Innovation Project, Ministry of Education of China (grant number NO704030).

1 Taubert G, Winkelmann BR, Schleiffer T, Marz W, Winkler R, Gok R, Klein B, Schneider $\mathrm{S}$, Boehm BO. Prevalence, predictors, and consequences of unrecognized diabetes mellitus in 3266 patients scheduled for coronary angiography. Am Heart J 2003; 145: 285-291.

2 Lauruschkat AH, Arnrich B, Albert AA, Walter JA, Amann B, Rosendahl UP, Alexander T, Ennker J. Prevalence and risks of undiagnosed diabetes mellitus in patients undergoing coronary artery bypass grafting. Circulation 2005; 112: 2397-2402.

3 Conaway DG, O'Keefe JH. Frequency of undiagnosed and untreated diabetes mellitus in patients with acute coronary syndromes. Expert Rev Cardiovasc Ther 2006; 4: 503-507.
4 Hu DY, Pan CY, Yu JM. The relationship between coronary artery disease and abnormal glucose regulation in China: the China Heart Survey. Eur Heart J 2006; 27: 2573-2579.

5 Ntyintyane LM, Panz VR, Raal FJ, Gill GV. Metabolic syndrome, undiagnosed diabetes mellitus and insulin resistance are highly prevalent in urbanised South African blacks with coronary artery disease. Cardiovasc J S Afr 2006; 17: 50-55.

6 Lee CM, Huxley RR, Lam TH, Martiniuk AL, Ueshema H, Pan WH, Welborn T, Woodward M. Prevalence of diabetes mellitus and population attributable fractions for coronary heart disease and stroke mortality in the WHO South-East Asia and Western Pacific regions. Asia Pac J Clin Nutr 2007; 16: 187-192.

7 Meier JJ, Deifuss S, Klamann A, Launhardt V, Schmiegel WH, Nauck MA. Plasma glucose at hospital admission and previous metabolic control determine myocardial infarct size and survival in patients with and without type 2 diabetes: the Langendreer Myocardial Infarction and Blood Glucose in Diabetic Patients Assessment (LAMBDA). Diabetes Care 2005; 28: 2551-2553.

8 Holper EM, Brooks MM, Kim LJ, Detre KM, Faxon DP. Effects of heart failure and diabetes mellitus on long-term mortality after coronary revascularization (from the BARI Trial). Am J Cardiol 2007; 100: 196-202.

9 Bypass Angioplasty Revascularization Investigation 2 Diabetes Study Group. Baseline characteristics of patients with diabetes and coronary artery disease enrolled in the Bypass Angioplasty Revascularization Investigation 2 Diabetes (BARI 2D) trial. Am Heart J 2008; 156: 528-536.

10 Norhammar A, Malmberg K, Diderholm E, Lagerqvist B, Lindahl B, Ryden L, Wallentin L. Diabetes mellitus: the major risk factor in unstable coronary artery disease even after consideration of the extent of coronary artery disease and benefits of revascularization. J Am Coll Cardiol 2004; 43: 585-591.

11 Lenzen M, Ryden L, Ohrvik J, Bartnik M, Malmberg K, Scholte Op Reimer W, Simoons ML. Diabetes known or newly detected, but not impaired glucose regulation, has a negative influence on 1-year outcome in patients with coronary artery disease: a report from the Euro Heart Survey on diabetes and the heart. Eur Heart J 2006; 27: 2969-2974.

12 Porter A, Assali AR, Zahalka A, lakobishvili Z, Brosh D, Lev EI, Mager A, Battler A, Kornowski R, Hasdai D. Impaired fasting glucose and outcomes of ST-elevation acute coronary syndrome treated with primary percutaneous intervention among patients without previously known diabetes mellitus. Am Heart J 2008; 155: 284-289.

13 Shepherd J, Barter P, Carmena R, Deedwania P, Fruchart JC, Haffner S, Hsia J, Breazna A, LaRosa J, Grundy S, Waters D. Effect of lowering LDL cholesterol substantially below currently recommended levels in patients with coronary heart disease and diabetes: the Treating to New Targets (TNT) study. Diabetes Care 2006; 29: 1220-1226.

14 Wild SH, Smith FB, Lee AJ, Fowkes FG. Criteria for previously undiagnosed diabetes and risk of mortality: 15-year follow-up of the Edinburgh Artery Study cohort. Diabet Med 2005; 22: 490-496.

15 Anselmino M, Bartnik M, Malmberg K, Ryden L. Management of coronary artery disease in patients with and without diabetes mellitus. Acute management reasonable but secondary prevention unacceptably poor: a report from the Euro Heart Survey on Diabetes and the Heart. Eur J Cardiovasc Prev Rehabil 2007; 14: 28-36.

16 Anselmino M, Ohrvik J, Malmberg K, Standl E, Ryden L. Glucose lowering treatment in patients with coronary artery disease is prognostically important not only in established but also in newly detected diabetes mellitus: a report from the Euro Heart Survey on Diabetes and the Heart. Eur Heart J 2008; 29: 177-184.

17 Okosieme OE, Peter R, Usman M, Bolusani H, Suruliram P, George L, Evans LM. Can admission and fasting glucose reliably identify undiagnosed diabetes in patients with acute coronary syndrome? Diabetes Care 2008; 31: 1955-1959.

18 Monterrosa AE, Haffner SM, Stern MP, Hazuda HP. Sex difference in lifestyle factors predictive of diabetes in Mexican-Americans. Diabetes Care 1995; 18: 448-456.

19 Kao WH, Puddey IB, Boland LL, Watson RL, Brancati FL. Alcohol consumption and the risk of type 2 diabetes mellitus: atherosclerosis risk in communities study. $A m \mathrm{~J}$ Epidemiol 2001; 154: 748-757.

20 Carlsson S, Hammar N, Grill V, Kaprio J. Alcohol consumption and the incidence of type 2 diabetes: a 20-year follow-up of the Finnish twin cohort study. Diabetes Care 2003; 26: 2785-2790.

21 Waki K, Noda M, Sasaki S, Matsumura Y, Takahashi Y, Isogawa A, Ohashi Y, Kadowaki T, Tsugane S. Alcohol consumption and other risk factors for self-reported diabetes among middle-aged Japanese: a population-based prospective study in the JPHC study cohort I. Diabet Med 2005; 22: 323-331.

22 Beulens JW, Rimm EB, Hendriks HF, Hu FB, Manson JE, Hunter DJ, Mukamal KJ. Alcohol consumption and type 2 diabetes: influence of genetic variation in alcohol dehydrogenase. Diabetes 2007; 56: 2388-2394.

23 Li Y, Zhang D, Jin W, Shao C, Yan P, Xu C, Sheng H, Liu Y, Yu J, Xie Y, Zhao Y, Lu D, Nebert DW, Harrison DC, Huang W, Jin L. Mitochondrial aldehyde dehydrogenase-2 (ALDH2) Glu504Lys polymorphism contributes to the variation in efficacy of sublingual nitroglycerin. J Clin Invest 2006; 116: 506-511.

24 Chen CH, Budas GR, Churchill EN, Disatnik MH, Hurley TD, Mochly-Rosen D. Activation of aldehyde dehydrogenase-2 reduces ischemic damage to the heart. Science 2008; 321: 1493-1495.

25 Dakeishi M, Murata K, Sasaki M, Tamura A, Iwata T. Association of alcohol dehydrogenase 2 and aldehyde dehydrogenase 2 genotypes with fasting plasma glucose levels in Japanese male and female workers. Alcohol Alcohol 2008; 43: 143-147.

26 Xu F, Chen YG, Geng YJ, Zhang H, Jiang CX, Sun Y, Li RJ, Sagar MB, Xue L, Zhang Y. The polymorphism in acetaldehyde dehydrogenase 2 gene, causing a substitution of Glu > Lys(504), is not associated with coronary atherosclerosis severity in Han Chinese. Tohoku J Exp Med 2007; 213: 215-220. 
27 Jo SA, Kim EK, Park MH, Han C, Park HY, Jang Y, Song BJ, Jo I. A Glu487Lys polymorphism in the gene for mitochondrial aldehyde dehydrogenase 2 is associated with myocardial infarction in elderly Korean men. Clin Chim Acta 2007; 382: 43-47.

28 Takagi S, Iwai N, Yamauchi R, Kojima S, Yasuno S, Baba T, Terashima M, Tsutsumi Y, Suzuki S, Morii I, Hanai S, Ono K, Baba S, Tomoike H, Kawamura A, Miyazaki S, Nonogi H, Goto Y. Aldehyde dehydrogenase 2 gene is a risk factor for myocardial infarction in Japanese men. Hypertens Res 2002; 25: 677-681.

29 Murata C, Suzuki Y, Muramatsu T, Taniyama M, Atsumi Y, Matsuoka K, Watanabe T, Okazaki I. Inactive aldehyde dehydrogenase 2 worsens glycemic control in patients with type 2 diabetes mellitus who drink low to moderate amounts of alcohol. Alcohol Clin Exp Res 2000; 24: 5S-11S.

30 Hines LM, Stampfer MJ, Ma J, Gaziano JM, Ridker PM, Hankinson SE, Sacks F, Rimm EB, Hunter DJ. Genetic variation in alcohol dehydrogenase and the beneficial effect of moderate alcohol consumption on myocardial infarction. N Engl J Med 2001; 344: $549-555$.

31 Du X, Kang JP, Lu Q, Nie SP, Wu JH, Zhang Y, Liu XH, Lu SZ, Chen F, Wu XS, Ma CS. Prevalence of unrecognized diabetes and risk factor control among patients with coronary heart disease and prognosis thereof. Zhonghua Yi Xue Za Zhi 2007; 87: 2829-2832.

32 Nomura T, Noma H, Shibahara T, Yokoyama A, Muramatusu T, Ohmori T. Aldehyde dehydrogenase 2 and glutathione S-transferase M 1 polymorphisms in relation to the risk for oral cancer in Japanese drinkers. Oral Oncol 2000; 36: 42-46.

33 Yokoyama T, Yokoyama A, Kato H, Tsujinaka T, Muto M, Omori T, Haneda T, Kumagai Y, Igaki $\mathrm{H}$, Yokoyama M, Watanabe $\mathrm{H}$, Yoshimizu $\mathrm{H}$. Alcohol flushing, alcohol and aldehyde dehydrogenase genotypes, and risk for esophageal squamous cell carcinoma in Japanese men. Cancer Epidemiol Biomarkers Prev 2003; 12: 1227-1233.

34 Narita M, Kitagawa K, Nagai Y, Hougaku H, Hashimoto H, Sakaguchi M, Yang X, Takeshita T, Morimoto K, Matsumoto M, Hori M. Effects of aldehyde dehydrogenase genotypes on carotid atherosclerosis. Ultrasound Med Biol 2003; 29: 1415-1419.

35 Wada K. Lifetime prevalence of alcohol drinking, cigarette smoking, and solvent inhalation among junior high school students in Japan: tradition and urbanization. Nihon Arukoru Yakubutsu Igakkai Zasshi 2001; 36: 124-141.

36 Gomberg ES. Treatment for alcohol-related problems: special populations: research opportunities. Recent Dev Alcohol 2003; 16: 313-333.

37 Muramatsu T, Wang ZC, Fang YR, Hu KB, Yan H, Yamada K, Higuchi S, Harada S, Kono $\mathrm{H}$. Alcohol and aldehyde dehydrogenase genotypes and drinking behavior of Chinese living in Shanghai. Hum Genet 1995; 96: 151-154.

38 Ding J, Li S, Wu J, Gao C, Zhou J, Cao H, Su PS, Liu Y, Zhou X, Chang J. Alcohol dehydrogenase-2 and aldehyde dehydrogenase-2 genotypes, alcohol drinking and the risk of primary hepatocellular carcinoma in a Chinese population. Asian Pac J Cancer Prev 2008; 9: 31-35.

39 Nathan C. Points of control in inflammation. Nature 2002; 420: 846-852.

40 Rizzo MR, Paolisso G, Grella R, Barbieri M, Grella E, Ragno E, Grella R, Nicoletti G, D'Andrea $F$. Is dermolipectomy effective in improving insulin action and lowering inflammatory markers in obese women? Clin Endocrinol (Oxf) 2005; 63: 253-258.

$41 \mathrm{Li} \mathrm{SY}$, Gilbert SA, Li Q, Ren J. Aldehyde dehydrogenase-2 (ALDH2) ameliorates chronic alcohol ingestion-induced myocardial insulin resistance and endoplasmic reticulum stress. J Mol Cell Cardiol 2009; 47: 247-255. 